\title{
A diversificação da produção familiar e aspectos ambientais: a qualidade do meio e as relações sociais entre agricultores familiares com o Instituto Chão
}

\author{
The diversification of family production and environmental aspects: the quality of the environment \\ and social relations between family farmers as a Ground Institute \\ La diversificación de la producción familiar y los aspectos ambientales: la calidad del medio \\ ambiente y las relaciones sociales entre los agricultores familiares como Instituto de Base
}

\section{Resumo}

A agricultura familiar consiste em uma prática de produção que viabiliza o gerenciamento da economia solidária, a diversidade produtiva, a soberania alimentar e espaço sustentáveis. O presente trabalho tem por finalidade verificar como a participação dos agricultores no Instituto Chão contribuiu para a diversificação produtiva, além de especificar modificações nas percepções sobre os meios de produção sustentáveis das unidades de produção agrícola. O método utilizado foi qualitativo com os atores envolvidos; em seguida, foram realizadas entrevistas semiestruturadas com agricultores familiares que comercializam diretamente com o Instituto Chão. Os resultados indicam que os agricultores familiares tiveram aumento da diversificação produtiva e na movimentação de cultivos, gerando maior rentabilidade, como a batata, com $11 \%$ das vendas, seguida de açafrão, vagem e feijão, com $8 \%$ das vendas. Em relação aos aspectos ambientais e agroecológicos, observou-se que $60 \%$ dos agricultores praticam o consórcio de atividades agrícolas e 55\% controlam as pragas e doenças da plantação com produtos naturais. As conclusões alcançadas mostram que a maior parte dos agricultores entrevistados se preocupa com o equilíbrio e a preservação dessas áreas.

Palavras-chave: Sustentável; Agricultura familiar; Feiras livres; Agroecologia; Preservação ambiental.

\begin{abstract}
Family farming consists in a production practice that enables the management of supportive economy, the productive diversity, food sovereignty and sustainable spaces. The present work has as aim verifying the form of how the participation of farmers in Instituto Chão contributed for the productive diversity, besides specifying changes in the perceptions about the sustainable means of production from the agricultural production. The applied methodology was of was qualitative whit of the actors involved; then, semi-structured interviews were realized with family farmers thar commercialized directly with Instituto Chão. The results indicate that the family farmers had some increase in the productive diversity and in the crop handling, generating bigger profitability, as the potato, with $11 \%$ of the Sales, followed by saffron, pods and beans, with $8 \%$ of the sales. In relation to the environmental and agro-ecological aspects, it was observed that $60 \%$ of the farmers practice the consortium of agricultural activities, $55 \%$ control plagues and diseases in the plantation with natural products, $35 \%$ use green fertilizing, $75 \%$ control weeds with natural weeding, $100 \%$ use animal manure and rests of plants and $85 \%$ know the term Agroecology. The conclusions reached show that a great part of the farmers worry about the balance and preservation of these areas.
\end{abstract}

Keywords: Sustainable development; Family farming; Free fairs; Agroecology; Environmental preservation.

\section{Resumen}

La agricultura familiar es una práctica productiva que posibilita la gestión de una economía solidaria, diversidad productiva, soberanía alimentaria y espacio sostenible. El presente trabajo tiene como objetivo verificar cómo la 
participación de los agricultores en el Instituto Chão contribuyó a la diversificación productiva, además de especificar cambios en las percepciones sobre los medios de producción sostenibles en las unidades de producción agrícola. El método utilizado fue cualitativo con los actores involucrados; luego, se realizaron entrevistas semiestructuradas con agricultores familiares que comercian directamente con el Instituto Chão. Los resultados indican que los agricultores familiares han incrementado la diversificación productiva y el movimiento de cultivos, generando una mayor rentabilidad, como la papa, con el $11 \%$ de las ventas, seguida del azafrán, el frijol y el frijol, con el $8 \%$ de las ventas. En relación a los aspectos ambientales y agroecológicos, se observó que el $60 \%$ de los agricultores practican actividades agrícolas intercaladas y el 55\% controlan plagas y enfermedades en la plantación con productos naturales. Las conclusiones alcanzadas muestran que la mayoría de los agricultores están preocupados por el equilibrio y la preservación de estas áreas.

Palabras clave: Desarrollo sustentable; Agricultura familiar; Ferias gratuitas; Agroecología; Preservación del medio ambiente.

\section{Introdução}

Segundo o MDA (2006), a agricultura familiar no Brasil está presente em 4.367.902 de estabelecimentos (24,3\%) e ocupa cerca de $70 \%$ de trabalhadores no campo. Portanto, mesmo detendo um espaço proporcionalmente limitado em extensão de terra, o agricultor familiar é responsável pela inserção produtiva de grande quantidade de trabalhadores. A produção familiar estabelece como prioridade a soberania alimentar, assegura o trabalho no campo e, com sua diversidade, é responsável por grande parte dos alimentos que chegam à mesa dos brasileiros (França; Del Grossi \& Azevedo Marques, 2009).

Deste modo, a produção familiar destaca-se pela dinamização do território rural, que recebe investimentos nos cultivos e favorece o estabelecimento de práticas que não prejudicam o meio ambiente (Santos, 2014). Com o uso das técnicas agroecológicas, que implicam um menor dano ao ecossistema, e métodos que utilizam uma grande variedade de cultivos em um mesmo espaço, é possível ao agricultor ampliar sua produção e assim diferenciar-se dos grandes proprietários de monocultura que vendem somente commodities para exportação (soja, milho, algodão, cana de açúcar e carne bovina).

Segundo Viegas (2010), Gaiger (2016) e Dweck (2019), a produção de alimentos dá-se pelo processamento e diversificação que leva a maiores rendimentos, investimento social e geração de empregos, tendo em vista que a diversificação produtiva familiar permite melhores condições de plantio e venda para os agricultores familiares.

Ademais, uma produção diversificada gera maiores possibilidades de conservação de variedades, que adquirem maior resistência a pragas e favorece o uso de sementes crioulas, e permite a heterogeneidade na comercialização de alimentos. Dentro deste contexto, os agricultores familiares estabelecem amplas alternativas de produção, além de permitirem o cultivo de grande parte dos alimentos que estão presentes na mesa dos consumidores.

Desta forma, a agricultura familiar de base ecológica procura se diferenciar da revolução verde, que priorizou a produção em grandes extensões de terra, uso de máquinas, agroquímicos e sistema de monocultura. Uma produção diversificada é definida pela utilização de práticas de uso e reaproveito de pequenas áreas para uma grande variedade de culturas alimentares. Segue-se que essa diversidade originou sistemas inovadores de comercialização que beneficiou tanto os produtores rurais quanto os consumidores (Sposito, 2017).

Os agricultores que praticam a diversidade da produção familiar são motivados pela crescente procura pelos mercados de produtos orgânicos que se encontram em rápida expansão, além de surgir como alternativa para os produtores rurais que tinham dificuldade de encontrar abertura nos mercados (Breitenbach, 2018). O aumento do consumo gerado por uma maior demanda faz com que os agricultores tenham que reorganizar seu sistema produtivo para atender as exigências atuais (Brandão, 2016).

Diante disso, o presente artigo busca analisar se com a participação do agricultor no Instituto Chão houve uma diversificação da produção familiar e verificar como funciona, por meio dos agricultores entrevistados, a preocupação com os meios de produção sustentáveis (agroecológica el ou orgânicos) das unidades de trabalho agrícola onde os produtores 
comercializam com o Instituto Chão. O método de pesquisa utilizado foi o qualitativo, no processo planejado de investigação iniciou-se o levantamento de perguntas relacionado aos problemas e questionamento do trabalho, na coleta de dados utilizou-se 20 formulários conforme a repetição dos atores envolvidos, e a análise e interpretação dos dados fez-se através de gráficos, quadros, foto e depoimentos.

O Instituto Chão é uma associação sem fins lucrativos que se movimenta para o aprofundamento da consciência crítica, da democracia e da igualdade de direitos, de modo a construir coletivamente uma sociedade que permita a cada um exercer sua liberdade. Trabalha-se com os princípios da Economia Solidária, uma forma de organização que coloca o ser humano como sujeito e finalidade da atividade econômica e busca a desmercantilização da força de trabalho ao articular redes e espaços de cooperação política, econômica e científica. Assim, articular e integrar redes que fomentem a autonomia, o cooperativismo, o comércio justo e o consumo consciente. Portanto, O Instituto Chão é um exemplo de venda de produtos da agricultura familiar em espaços urbanos e tem como foco o comércio justo e solidário. Com sede na Rua Harmonia, 123 - Vila Madalena, São Paulo - SP, fundada em maio de 2015, o Instituto tem como objetivo a valorização econômica e social dos agricultores.

O presente estudo analisa a diversificação da agricultura familiar após a comercialização com o Instituto Chão e a mudança na percepção dos agricultores em relação aos meios de produção sustentáveis das unidades de produção que passaram a comercializar com o Instituto; além disso, foi possível verificar a qualidade do ambiente, a qualidade do trabalho, das relações sociais e do alimento.

O texto organiza-se em quatro sessões, além desta introdução. Em primeiro lugar é exposta à importância da diversidade produtiva para os agricultores e os sistemas sustentáveis de plantio. A segunda parte discute os procedimentos metodológicos. A terceira parte do trabalho retrata os resultados, discussão e a parte quatro expõe as conclusões do trabalho.

\subsection{A importância da diversidade produtiva para os agricultores e os sistemas sustentáveis}

A partir da década de 1990, com os programas de incentivo a agricultura familiar, como o Programa Nacional de Fortalecimento da Agricultura Familiar (PRONAF), o Programa de Aquisição de Alimentos (PAA) e o Programa Nacional de Alimentação Escolar (PNAE), a agricultura familiar passa a ampliar sua produção para atender a essas novas demandas; também se verifica uma ampliação de sua participação em feiras livres e fornecimento de cestas de alimentos que conectaram o produtor rural com o consumidor. Assim, busca-se uma viabilidade econômica através do fortalecimento dessas redes de comercialização direta. Consequentemente, a diversidade produtiva passou a ser cada vez mais apontada como uma alternativa viável e recomendável para os agricultores familiares.

Contudo, o agricultor familiar se depara com algumas limitações para a realização de uma produção diversificada, além da falta de infraestrutura e da falta de recursos para investimento na propriedade para promover a diversidade produtiva. Como descreve Darolt (2013), o desenvolvimento sustentável no campo está relacionado com a biodiversidade, à melhoria ambiental e das condições de saúde e infraestrutura mais adequadas para o trabalhador rural. Brandão (2015) sugere que a diversidade produtiva, quando bem estruturada, tem financiamento e planejamento, podendo reorganizar a cadeia produtiva e possibilitar uma adesão maior dos produtores familiares para atender as exigências atuais.

Como apresenta Darolt (2013) e Brandão (2015), pode-se considerar que a diversidade produtiva está relacionada com uma junção de diversos atores sociais e econômicos. Os agricultores familiares procuram relações comerciais que estabeleçam trocas mais justas e que priorizam uma produção mais heterogênea, além do apoio técnico e comercial para essas demandas produtivas que possam escoar com maior qualidade e benefício para o produtor e o consumidor. Dessa maneira, feiras livres, associações e cooperativas constituem uma alternativa para os agricultores familiares, pois além da comercialização mais justa, reitera o apoio técnico e incentivo a uma produção de diversos cultivos. 
Com isso, as relações de agricultores e associações destacam-se pelas contribuições no desenvolvimento socioeconômico e na variedade produtiva. As práticas de cooperação entre agricultores familiares e associações levam a soberania alimentar, pois uma parte da produção permanece com o agricultor e o excedente é negociado em feiras, sendo o apoio nessa relação comercial a base para a diversidade produtiva como fonte para melhorar as condições sociais e econômicas. Assim, o agricultor familiar e as cooperativas geram um valor agregado ao produto comercializado, criando um aumento significativo das demandas pelos produtos (Cazella, 2010; Tesche, 2013 ; Lima, 2017 \& Shultz; 2017).

Ademais, o agricultor familiar reconhece nas novas práticas de cultivo um maior conhecimento da qualidade do ambiente e do alimento, redução dos custos e fortalecimento da economia rural (Ploeg; 2000). Como cita Kageyana (2008) e Pierri (2011), o meio urbano, através da oferta de bens e serviços, trazem ao agricultor familiar maiores oportunidades de diversidade de atividades agrícolas. A agricultura familiar passa a ser reconhecida como um modelo de produção sustentável (Grisa, 2019), o que estimula um sistema de trabalho que almeje o desenvolvimento local e a qualidade de vida do produtor rural, pois nessa relação de cultivo em que há o respeito ao meio ambiente e às relações sociais, há um fortalecimento da rede de solidariedade entre esses agentes sociais (Poulain, 2018).

\section{Metodologia}

A presente pesquisa é do tipo qualitativo. Foram realizadas entrevistas com os agricultores familiares do assentamento Belas Vista Iperó (SP), e os da cidade de Cristina (MG). No total, são 40 agricultores, dos quais 30 participam da venda para a Associação Instituto Chão. As entrevistas foram finalizadas com 20 agricultores pelo método de repetição dos atores envolvidos. Os formulários correspondem a perguntas abertas com a proposta de entrevistas individuais, e a técnica utilizada foi a "bola de neve".

De acordo com Vinuto (2014), o método nomeado de "bola de neve" utiliza cadeias de referência, e o desejo de melhor compreensão sobre um tema, testar a viabilidade de realização de um estudo mais amplo, e desenvolver os métodos a serem empregados em todos os estudos ou fases subsequentes. Na metodologia destaca-se pesquisas que utilizam o estudo de caso para analisar as organizações de pequenos produtores, destes referenciais foram utilizados os seguintes autores (Nascimento, 2015; Koutou, 2016; Del Viso, 2017; Pereira, 2017; Pena-Rueda,2019 \& Guareschi, 2020). Portanto, a presente pesquisa destaca-se pela aceitabilidade do método, na interpretação do fenômeno observado a partir de vários ângulos e utilização de diferentes fontes e a descrição dos resultados com base na organização e nas informações dos dados pelo pesquisador. A pesquisa de campo foi realizada de novembro a dezembro de 2019; foram realizadas visitas no Instituto Chão e nas propriedades dos agricultores familiares, possibilitando recolhimento dos dados, entrevistas e fotografias das dinâmicas do trabalho rural. Os formulários foram aprovados pelo Comitê de Ética na Pesquisa bem como os termos de Consentimento Livre e Esclarecido. 
Figura 1 - Localização geográfica do Município de Cristina (MG).

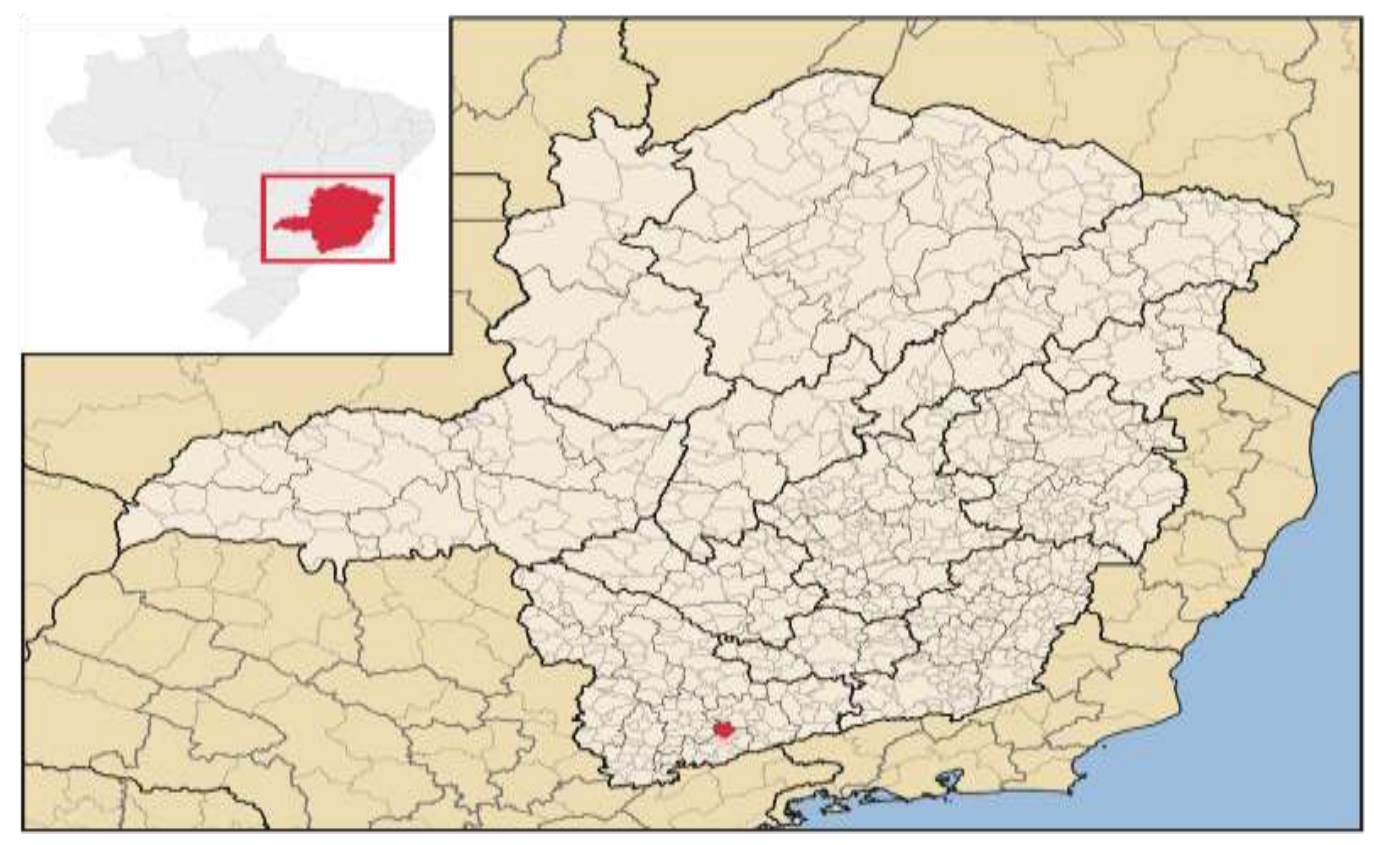

Fonte: Elaborado pelos autores (2019).

Figura 2 - Localização geográfica do município de Iperó (SP)

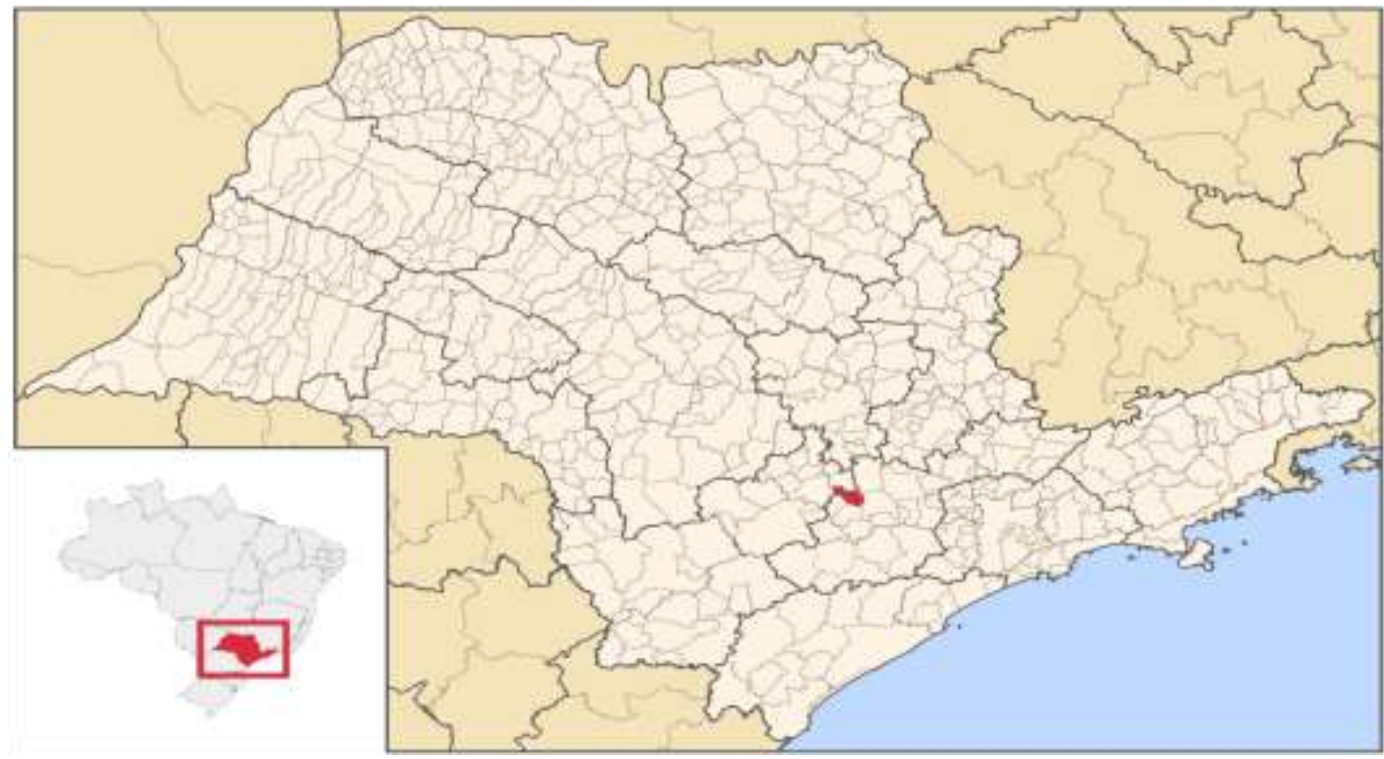

Fonte: Elaborado pelos autores (2019).

A análise e o tratamento dos dados da pesquisa pautaram-se pelo levantamento de campo dos dados primários de formulários semiestruturados que foram aplicados aos agricultores familiares e cooperados que comercializam diretamente com o Instituto. Os dados obtidos através dos formulários permitem caracterizar os atores envolvidos, suas percepções e estratégias de comercialização e cooperativismo.

\section{Resultados e Discussão}

Esta seção apresenta os dados da pesquisa com base no quesito Diversificação da Produção Familiar e Aspectos Ambientais e Agroecológicos dos agricultores familiares que comercializam com o Instituto Chão como: diversificação e 
produção; estabelecimentos de comercialização, trabalho e adaptações nas técnicas produtivas, relações sociais e o alimento; coleta de plantas nativas e preservação ambiental; cultivo orgânico, controle de plantas invasoras e controle de pragas, adubação e conhecimentos agroecológicos.

\subsection{Diversificações da produção dos agricultores familiares}

Os agricultores relatam que já existia uma diversidade produtiva, mas com a entrada do Instituto alguns alimentos passaram a ser mais produzidos e, assim, a diversificação possibilitou maior renda aos agricultores.

A Figura 3 ilustra as fontes de renda da média dos 20 agricultores que geraram maior volume de venda. Pela Figura 3 , nota-se a batata com $11 \%$ das vendas, seguida do açafrão, vagem e feijão com $8 \%$ das vendas.

Figura 3 - Atividades com maior fonte de renda dos agricultores familiares dos municípios de Iperó (SP) e Cristina (MG).

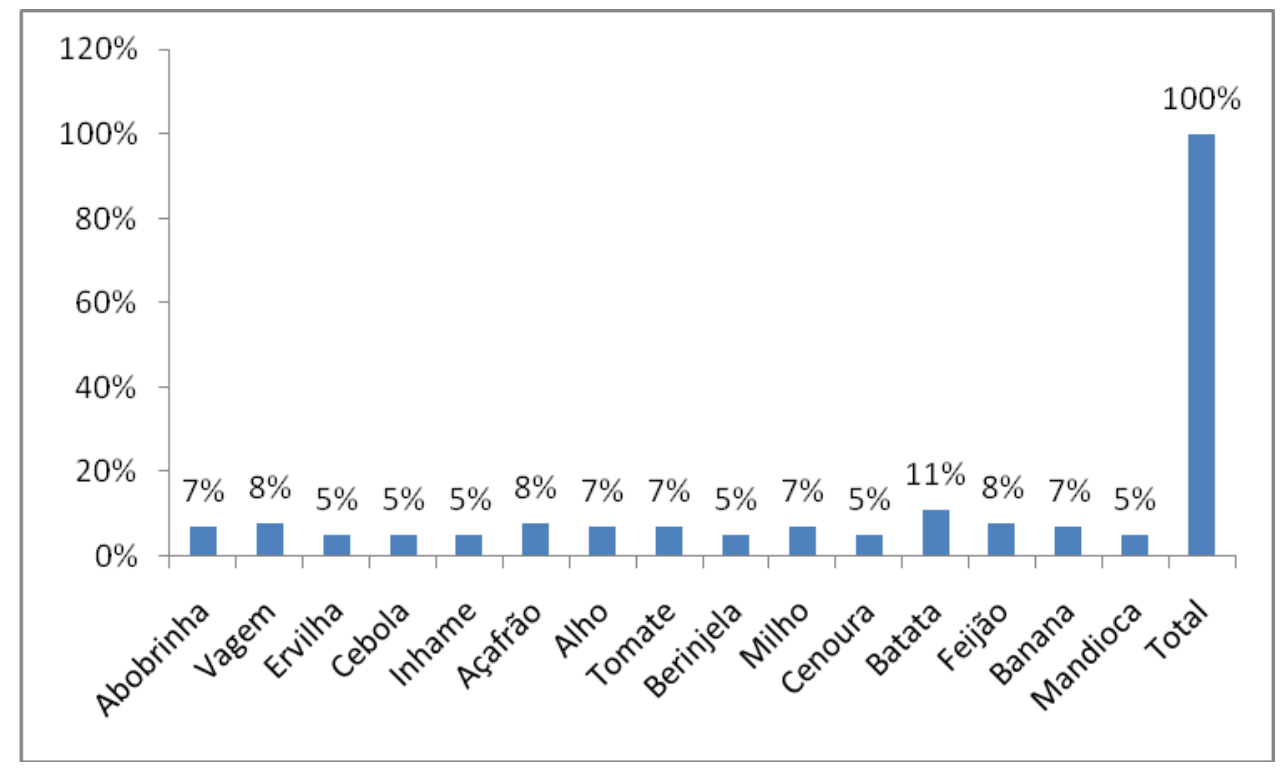

Fonte: Pesquisa de Campo (2019).

No Quadro1, observa-se grande variedade dos produtos que passaram a ser produzidos após a comercialização com o Instituto Chão, demonstrando que além dos novos cultivos e demandas nessa relação entre agricultores e associação, trouxe também, maior fonte de renda aos produtores conforme apontado pela Figura 3. 
Quadro 1 - Produtos que passaram a ser produzidos pelos agricultores após a comercialização com o Instituto Chão.

\begin{tabular}{|c|c|c|c|c|}
\hline \multirow[t]{12}{*}{ Produtos } & \multicolumn{2}{|c|}{ Antes do Instituto Chão } & \multicolumn{2}{|c|}{ Depois do Instituto Chão } \\
\hline & Abobrinha & Cenoura & Batata & Couve \\
\hline & Ervilha & Beterraba & Açafrão & Alho Poro \\
\hline & Cebola & Pêssego & Vagem & Alecrim \\
\hline & Inhame & Nabo & Abobrinha & Hortelã \\
\hline & Alho & & Feijão & Abobrinha \\
\hline & Tomate & & Banana & Ervilha \\
\hline & Berinjela & & Abacate & Cebola \\
\hline & Pimentão & & Limão & Inhame \\
\hline & Quiabo & & Laranja & Alho \\
\hline & Nabo & & Cebolinha & Tomate \\
\hline & Rabanete & & Almeirão & Pepino \\
\hline
\end{tabular}

Fonte: Pesquisa de Campo (2019).

Na pesquisa, verificou-se que a vinculação dos agricultores com o Instituto acrescentou uma diversificação produtiva, além de proporcionar novas demandas. Esse processo levou o Instituto a propor aos agricultores novos cultivos segundo as possibilidades e infraestrutura desses locais. Assim, através desse acordo, alguns produtos passaram a ser cultivados e comercializados, como: batata, açafrão, feijão, hortaliças e fruticultura.

\subsection{Formas de comercialização dos agricultores}

Em relação aos meios que esses produtos são comercializados, constatou-se pela Figura 4 que 23\% produtos são comercializados com o Instituto Chão, 23\% em feiras livres, $12 \%$ são distribuídos em vendas diretas para os consumidores, $12 \%$ das mercadorias são comercializadas com restaurantes, $11 \%$ são entregas de cestas, $8 \%$ são supermercados, $7 \%$ lojas e 4\% de produtos são comercializados por meio do Programa Nacional de Alimentação Escolar (PNAE) e Programa de Aquisição de Alimentos (PAA). 
Figura 4 - A comercialização dos agricultores de Iperó (SP) e Cristina (MG).

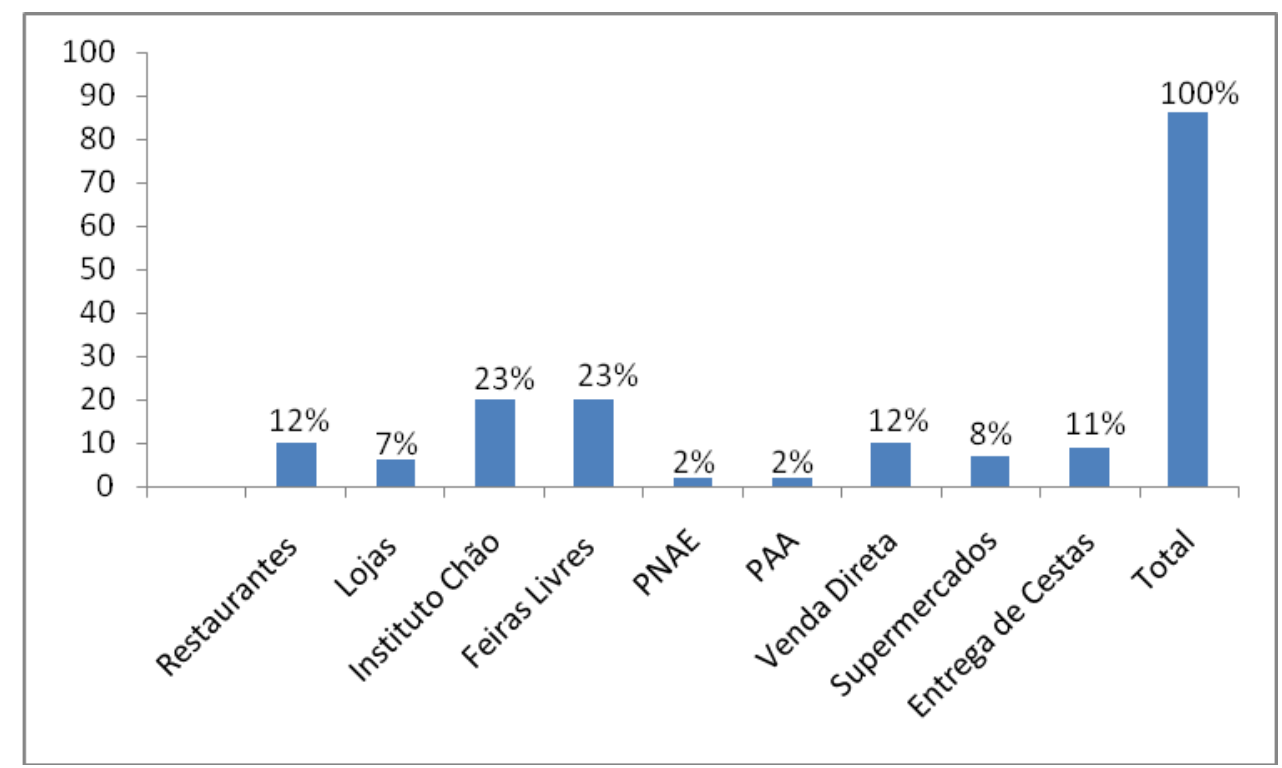

Fonte: Pesquisa de Campo (2019).

Esses dados da Figura 4 evidenciam a importância das feiras livres e das Associações como o Instituto Chão para os agricultores familiares. As associações se tornaram instrumentos valiosos para a regularidade das vendas e garantia segura da renda no campo. Como descreve Cabral (2015), a garantia da venda dos agricultores familiares realiza-se pela participação da comercialização com as Associações, que possibilita o desenvolvimento local.

\subsection{Mudanças e adaptações nas técnicas produtivas}

A Tabela 1 apresenta as mudanças e adaptações que os agricultores realizaram pelo incentivo à diversificação produtiva. 
Tabela 1 - Respostas às abordagens se houve diversificação da produção e quais adaptações foram necessárias após a comercialização com o Instituto Chão.

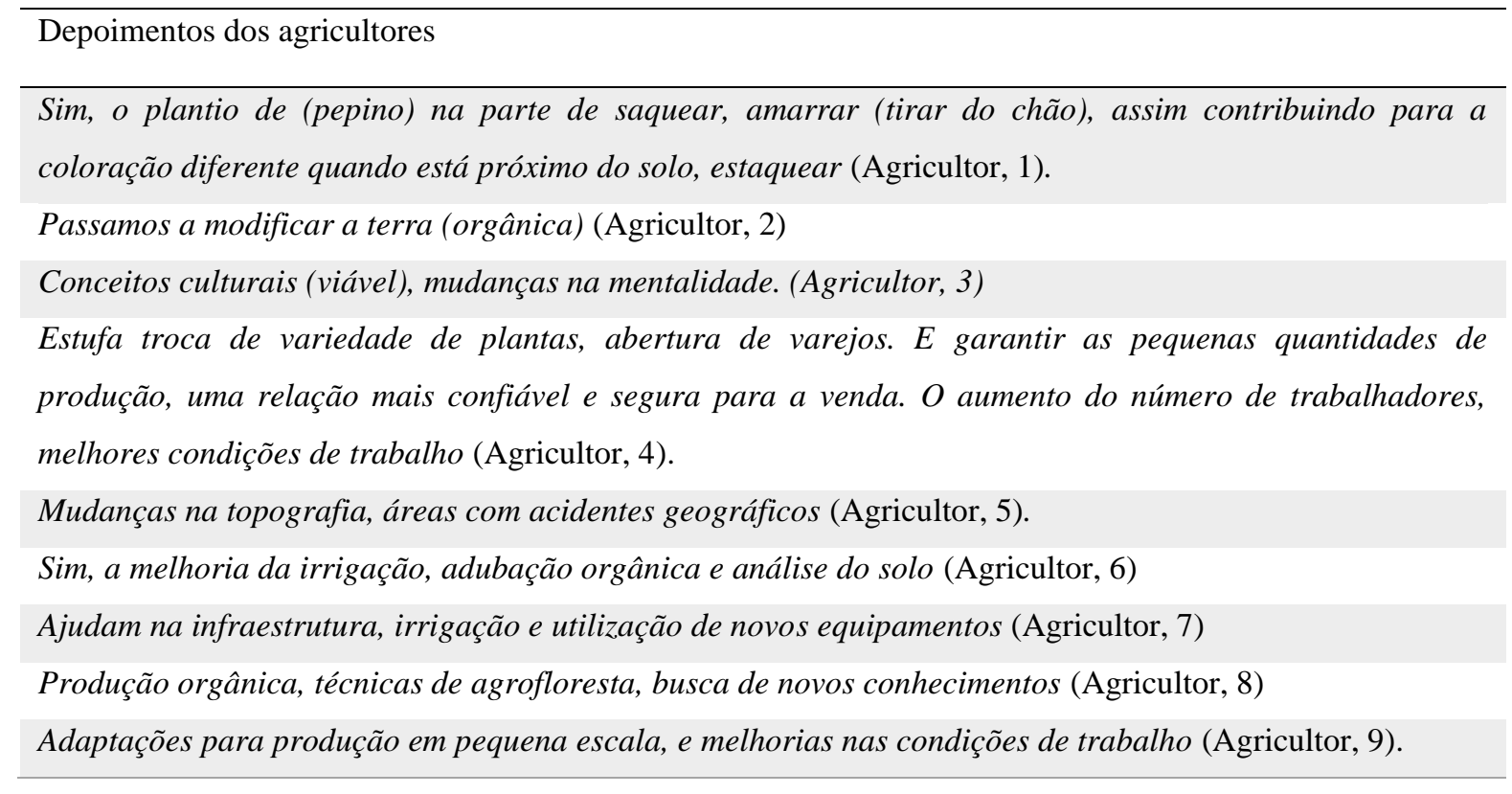

Fonte: Pesquisa de Campo (2019).

Na Tabela 1, percebe-se que a diversificação produtiva depois da comercialização com o Instituto levou muitos agricultores a investirem em melhores condições de cultivo, produção e trabalho.

Sobre as potencialidades e dificuldades do agricultor familiar, Soares (2015) relata em seu estudo que os agricultores, quando estabelecem uma regularidade de venda e uma estrutura mínima de trabalho, conseguem ser mais produtivos e adaptáveis às exigências do mercado. No caso da presente pesquisa, pelos relatos são observadas as dificuldades e potencialidades presenciadas com a comercialização para o Instituto Chão:

“A gente planeja entregar para o Instituto Chão, dentro da nossa prática de agricultura; às vezes, o Instituto tem demandas de alimentos que não temos estrutura suficiente para produzir, por exemplo, alface o ano todo. A gente não tem condições, não temos a estufa; produzir tomate (não tem estufa, não tem irrigação), problemas com água suficiente; para inovar no campo de produção, na qualidade que o Instituto quer e deseja, precisa ter essa infraestrutura" (Agricultora, Iperó, SP, 2019).

Se a gente 'os assentados' tivesse uma infraestrutura adequada nós poderíamos ter um volume de produção que satisfizesse o Instituto Chão por conta do que eles teriam de demanda de compra. Por outro lado, devemos valorizar e assegurar se não tivesse o Instituto Chão, todo esse número de familiares estaria em desalento do ponto de vista agroecológico e, certamente desestimularia a produção orgânica, e voltariam para a produção convencional, para o mercado comum; essa qualidade de ter o Instituto Chão permeando e construindo com os agricultores é imensa (Agricultor 3,Cristina, MG, 2019).

Desse modo, na agricultura familiar se observam agricultores que já detém uma estrutura mínima de trabalho, como estufas, maquinários e irrigamento e, portanto, tiveram melhores condições de inovar e investir na produção com a melhoria da renda; outra parte desses trabalhadores não dispõe de estrutura adequada e, portanto, não conseguem ampliar e aumentar e diversificar a produção. 


\subsection{Comercialização solidária e o desenvolvimento social e econômico}

A Tabela 2 retrata as respostas dos agricultores sobre a construção de uma comercialização solidária e baseada na confiança, verificando se a mesma trouxe um maior desenvolvimento para os agricultores.

Tabela 2 - Percepções sobre a comercialização solidária e sua importância para o desenvolvimento social e econômico.

Depoimentos dos agricultores

Sim, através da confiança, as relações são preestabelecidas (Agricultor, 8).

Sim, auxilia na qualidade dos alimentos, relações de trabalho mais igualitárias e um pagamento mais justo (Agricultor, 9).

Sim, ajuda os agricultores e as associações (Agricultor, 10).

Sim, contribui ao acesso do consumidor, além de um preço mais justo (Agricultor, 11).

Sim, auxilia a chegada do produto ao consumidor, mais barato e maior produtividade (Agricultor, 12).

Sim, a experiência coletiva e solidária, forma-se um grupo de venda (carteira de clientes) dentro de uma organização solidária, que planeja a divisão da produção por partes, para que todos sejam contemplados (Agricultor, 13).

Sim, a comercialização solidária e baseada na confiança trouxe uma mudança nas relações de trabalho e na própria produção (que era vendida como convencional) e agora com a Associação teve melhoria na renda (Agricultor, 14).

Sim, possibilitou a discussão (a comunidade, ampliar o pobre no orgânico), além de uma alternativa ao mercado convencional do orgânico (Agricultor, 15).

Fonte: Pesquisa de Campo (2019).

Em relação às relações sociais e o alimento, a Tabela 2 permite observar que a comercialização solidária trouxe aos agricultores familiares uma nova alternativa de comércio e conhecimento sobre o alimento que produz. $\mathrm{O}$ agricultor familiar, quando garante uma relação comercial mais justa e solidária, baseada na credibilidade e confiança passa a ter no seu trabalho uma relação de parceria, desenvolvimento do comércio justo e valorização de toda a logística da construção social dos mercados (Santos, 2016).

O alimento se apresenta como um dispositivo de cooperação e integração entre os que produzem e vendem e os que compram e consomem através de técnicas e processos agroecológicos que não agridem o meio ambiente e permitem relações de trabalho baseadas no comércio justo e economia solidária, sendo possível garantir a soberania alimentar e nutricional (Bergamasco, 2013).

\subsection{Aspectos ambientais e agroecológicos}

Os 95\% dos estabelecimentos providos com brejos, rios e riachos são apresentados conforme a Figura 5. Pela pesquisa foi possível observar que a maior parte dos agricultores se preocupa com o equilíbrio e a preservação dessas áreas.

Como mostra a Figura 5, 60\% dos agricultores familiares pesquisados praticam consórcio de atividades agrícolas, e $85 \%$ conhecem o termo agroecologia, além de utilizarem as suas práticas no cultivo e colheita. 
Figura 5 - Aspectos Ambientais e Agroecológicos.

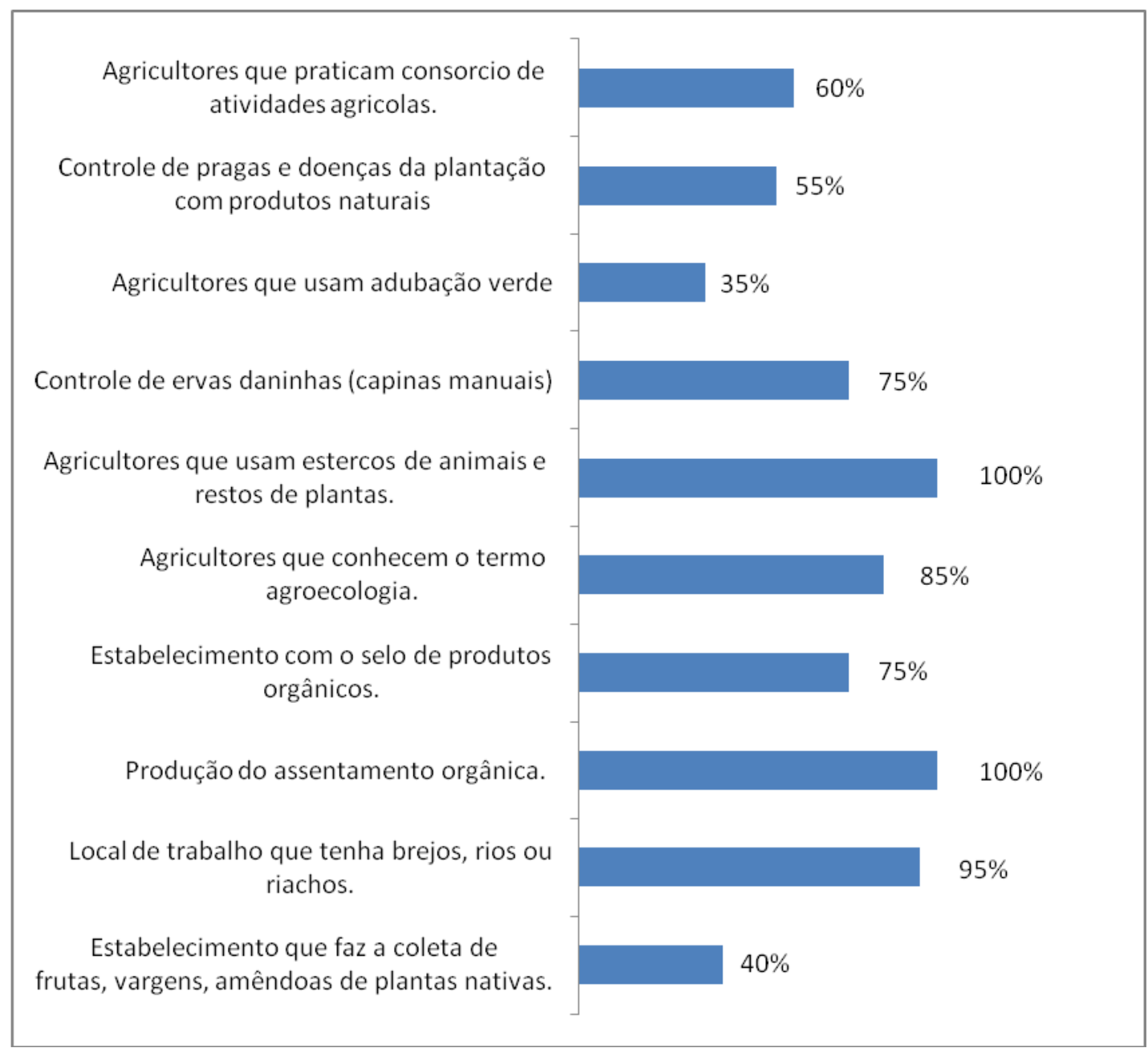

Fonte: Pesquisa de Campo (2019).

Na Figura 5 também é possível verificar que 55\% dos agricultores controlam as pragas e doenças da plantação com produtos naturais; 35\% usam adubação verde; e 75\% utilizam as capinas naturais para o controle das ervas daninhas. Desse modo, os agricultores, no controle de plantas invasoras, utilizam roçadeira, capina, enxada, cobertura morta, plantas repelentes e caldas. No controle de pragas e doenças são utilizadas receitas caseiras, caldos, pimenta, solo equilibrado, plano de manejo e produtos permitidos na produção orgânica. Na adubação, $100 \%$ dos produtores usam estercos de animais e restos de plantas. Além disso, constatou-se que $100 \%$ dos agricultores pesquisados têm produção orgânica.

Portanto, os agricultores verificaram que através de um cultivo agroecológico passaram a ter uma preocupação maior com um modelo sustentável de produção. Assim, verificaram-se a busca por métodos que utilizem adubação verde, produtos naturais, estercos de animais e restos de plantas.

Também foi observado nas unidades produtivas um empenho na entrega de produtos que atendam aos requisitos da produção orgânica, além da utilização de métodos para preservar a qualidade do meio, como: conservação da vegetação nativa, a utilização do sistema agroflorestal, adubação e pastagem ecológica.

\subsection{A agroecologia e a agricultura familiar}

Na Tabela 3 são apresentados os registros das entrevistas e a percepção dos agricultores sobre a agroecologia e a sua importância para os agricultores familiares. Os resultados indicados demonstraram como os princípios e características da 
agroecologia são importantes nas relações do trabalho, no convívio com o ambiente e a própria qualidade da alimentação em si.

Tabela 3 - Percepções dos agricultores sobre a importância da Agroecologia.

Depoimentos dos agricultores

A agroecologia é necessária, pois traz benefícios ao ambiente e ao ser humano (Agricultor, 1).

Possível harmonia com a natureza (Agricultor, 2).

Relação do agricultor com as questões ambientais, sociais e culturais (Agricultor, 3).

Bom, traz melhorias, evita agrotóxicos, leva um produto de primeira qualidade para os consumidores (Agricultor, 4).

Agroecologia é um conjunto de teoria e postulados que propõe que a produção reporte ao meio ambiente, que as possibilidades de que a produção seja sustentável (Agricultor, 5).

A permanência de um solo mais fértil, saudável e equilibrado (Agricultor, 6).

Uma visão de conjunto, olhar a produção agrícola e pecuária com respeito à natureza e a própria viabilidade econômica (Agricultor, 7).

Política Pública (não tem incentivo) acesso a equipamentos e a políticas para um cultivo adequado e uma comercialização que facilite os agricultores familiares (Agricultor, 8).

A agroecologia trouxe uma parceria dos produtores que estão sozinhos e com dificuldades de vendas, através da articulação com as redes solidárias (Agricultor, 9).

Importante, bom para as plantas e árvores (Agricultor, 10).

Deixar a biodiversidade biológica, ciclos que não pode usar, quanto menos mexer na natureza ela repousa (Agricultor, 11).

Agroecologia, uma boa opção, produzir alimentos sem agrotóxicos e venenos, conseguindo trabalho com as vendas para as escolas (Agricultor, 12).

Cultivar um método auto-sustentável, sem agredir o meio ambiente, não comprar insumo e utilizar o que a própria natureza oferece para a gente (Agricultor, 13).

Fonte: Pesquisa de Campo (2019).

\subsection{Sistema agroflorestais (SAF) e diversidade produtiva}

Os sistemas Agroflorestais ou SAF são um complexo produtivo que se baseia na sucessão ecológica, semelhantes aos ecossistemas naturais, em que árvores nativas são consorciadas nas culturas agrícolas.

Na Figura 6 é possível visualizar o SAF e a diversidade produtiva. 
Figura 6 - Imagens do SAF no plantio do agricultor.

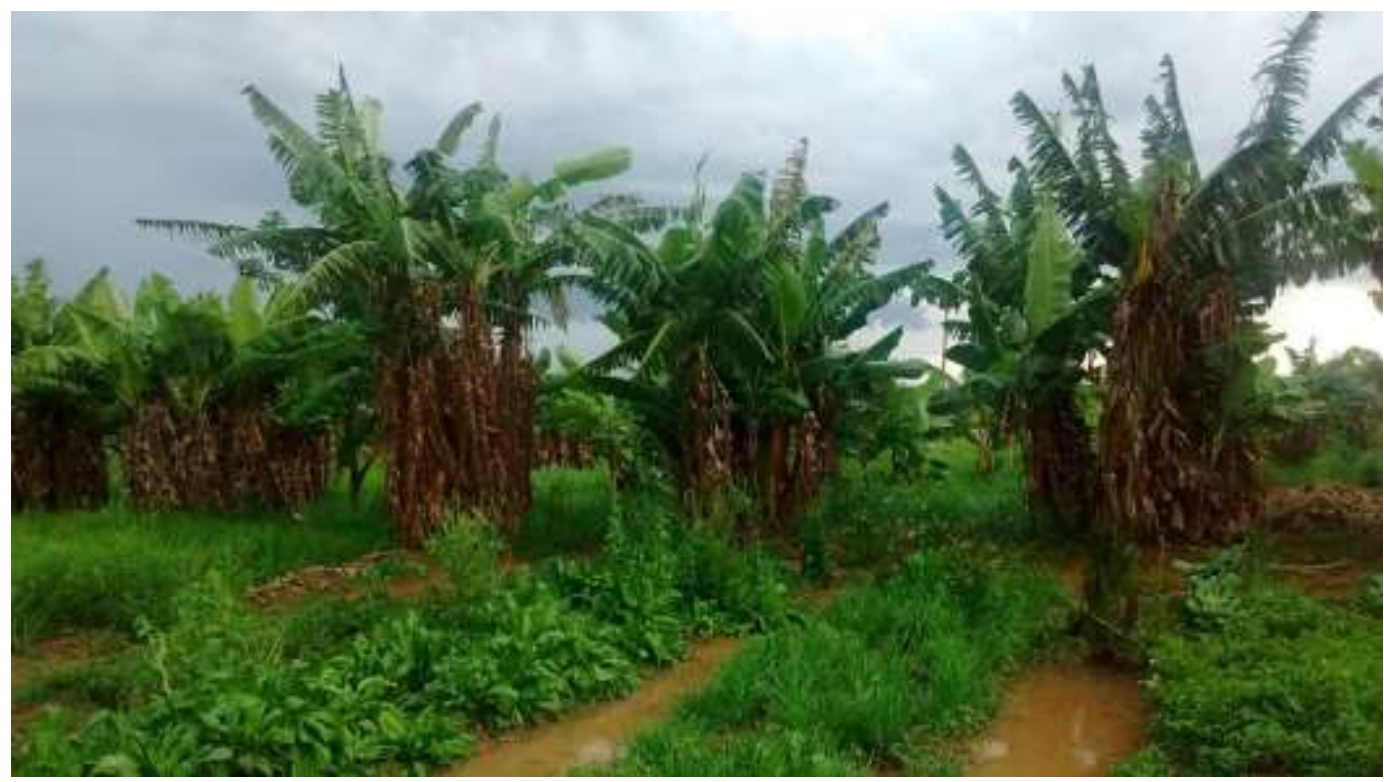

Fonte: Pesquisa de Campo (2019).

Na Figura 6, o SAF se mostra como um sistema produtivo com a combinação de diversas culturas agrícolas com árvores frutíferas na mesma área, e buscando um equilíbrio entre o solo, água e energia. O seu uso e manejo seguem as diretrizes da não utilização de agrotóxicos, a ciclagem de nutrientes e a produção de matéria orgânica no sistema de melhoria do solo e exploração de hortaliças que podem ser vendidas no curto prazo.

Nesse cultivo, os agricultores demonstram um esforço para aprimorar suas técnicas, aperfeiçoar seus conhecimentos e obter um maior entendimento da variedade na produção e comercialização.

Conhecer o período, quais são as plantas que combinam entre si, plantas que combinam com a raiz, e a gente vai usar a folha, ciclo rápido, uma planta que é mais adubadeira pode ser colocada em determinado espaço (adubação de verão e inverno). O ambiente deve estar de acordo com a estação, a cobertura, microbiota do solo, usar menos água, proteção da luz do sol, o solo, conforto térmico e a amplitude térmica (matéria orgânica) as árvores vão ganhando tamanho e vigor, mudança da temperatura, relação de umidade e vento no espaço (Agricultor 5, Iperó, SP, 2019).

Ao aprimorar as técnicas e conhecimentos e, consequentemente, obter a diversidade produtiva conforme supramencionado, a associação Instituto Chão com seu espaço de feira livre proporciona aos agricultores familiares vendas para a sua produção, além de promover uma comercialização que priorize a diversidade dos cultivos alimentares, conforme o caso apresentado. Ademais, trabalhos como de Silva (2016) e Lima (2019) sugerem que as associações e cooperativas são alternativas para a comercialização e ampliação de novos cultivos.

\section{Considerações Finais}

Os agricultores familiares mencionados na pesquisa apresentam maior variedade produtiva, melhoria na qualidade do meio e nos aspectos ambientais e agroecológicos.

Pela pesquisa de campo, observou-se que o Instituto Chão na sua comercialização com os agricultores familiares, trouxe novas demandas no plantio, além de acrescentar produtos que detém um maior valor agregado no mercado, assim 
possibilitando um maior rendimento e diversidade produtiva. Entretanto, nessa análise percebeu-se que muitos agricultores descrevem que somente os que detêm uma estrutura mínima para cultivar esses produtos passam a receber maiores benefícios.

Os resultados da pesquisa permitiram verificar que a participação dos agricultores em comercialização com o Instituto Chão proporcionou uma maior diversificação da produção familiar. Observou-se a importância da associação Instituto Chão e as feiras livres para os agricultores familiares. As associações se tornaram um importante instrumento para o aumento da renda desses agricultores e do acesso ao alimento.

Essa comercialização estimulou entre os agricultores a implantação e aumento dos cultivos, assim criando 11 novos cultivos que passaram a ser produzidos e vendidos na agricultura familiar. Através da pesquisa, percebeu-se ainda que o produtor rural, quando garante uma relação comercial mais justa e solidária, baseada na credibilidade e na confiança obtém no seu trabalho uma relação de cooperação, melhoria na qualidade do meio, nas suas próprias relações sociais e no próprio entendimento da importância do alimento na sua vida e para o comprador final do produto.

Sobre os aspectos ambientais e agroecológicos, conclui-se que os agricultores passaram a cultivar e produzir alimentos que tenham modelos e técnicas com exigências e características da agricultura orgânica, como o uso de produtos naturais, adubação verde, capinas manuais, estercos de animais e restos de plantas.

Este trabalho possibilita refletir sobre a importância em estudos mais aprofundados sobre associações e cooperativas que comercializam com agricultores familiares, além de medidas de extensão rural que proporcionem ao agricultor maior conhecimento nas suas práticas de cultivo, adaptações na qualidade do meio e melhorias nas condições de trabalho.

\section{Referências}

Bergamasco, S. M. P. P., Souza-Esquerdo, V. F. de., Oliveira, J. T. A. de., \& Érika de, S.(2013). Segurança alimentar e nutricional e qualidade de vida em assentamentos rurais. Segurança Alimentar e Nutricional 20(1), 13-23

Brandao, J. B. (2016). A gestão da cadeia de suprimentos das redes regionais de varejo de frutas, legumes e verduras no Rio Grande do Sul:um estudo multicaso.Extensão Rural, Santa Maria, 23(3), 51-68

Breitenbach, R. (2018). Participação econômica das atividades de subsistência na agricultura familiar. Redes, Santa Cruz do Sul, 23(1), 53-68. ISSN 19826745. <https://online.unisc.br/seer/index.php/redes/article/view/6780. https://doi.org/10.17058/redes.v23i1.6780>

Cabral, F. F., Cardoso, M. A., Junior, S. S., \& Teixeira, S. O. (2015). Agricultura Familiar e Programação de Aquisição de Alimentos no Estado de Mato Grosso. Revista de Estudos Sociais, [S.1.], 17(34), 78-92. <https://periodicoscientificos.ufmt.br/ojs/index.php/res/article/view/2590>

Cazella, A. A., Burigo, Fábio, L., \& Capellesso, A. J. (2010). Redes de cooperação: das artes de pesca à inovação financeira. Extensio: Revista Eletrônica de Extensão, Florianópolis, p. 41-57. ISSN 1807-0221. <https://periodicos.ufsc.br/index.php/extensio/article/view/14395>. https://doi.org/10.5007/18070221.2010v7nespp41.

Darolt, M. R. (2013). A diversidade dos circuitos curtos de alimentos ecológicos: ensinamentos do caso brasileiro e francês. Construção Social dos Mercados, $10(2)$, p.8

Del Viso, N., Fernandez Casadevante, J. L., \& Moran, N. (2017). Cultivando as relações sociais. O comum e a "comunidade" através da experiência de duas hortas urbanas em Madrid. Journal of Social Anthropology, 26(2), 473-481, 11.

Dweck, E. (2019). Quando a economia é vista como ciência exata, saídas para crises são restritas a dados numéricos. <http://www.ihuonline.unisinos.br/artigo/7589-quando-a-economia-e-vista-como-ciencia-exata-saidas-para-crises-sao-restritas-a-dados-numericos>

França, C. G., Del Grossi, M. E., \& Azevedo, M. V. P. M. (2009). O censo agropecuário e a agricultura familiar no Brasil. Brasília: MDA. 96p.

Gaiger, L. I. G. (2016). A descoberta dos vínculos sociais: os fundamentos da solidariedade. - São Leopoldo: Ed. Unisino.

Guareschi, M., Maccari, M., Sciurano, J. P. A. F., \& Pronti, A. (2020). "Uma Abordagem Metodológica para um Sistema Agroecológico de Alta Escala em EU-LAFSs: O Caso do Bio-Distrito de Parma" Sustentabilidade 12, no. 13: 5398. https://doi.org/10.3390/su12135398.

GIL, A. C. (1994). Métodos e técnicas de pesquisa social. (4ª . ed.): Atlas.

Gil, A. C. (2007). Como elaborar projetos de pesquisa. (4ª . ed.): Atlas.

Grisa, C., \& Niederle, P. (2019). Transferência, Convergência e Tradução de Políticas Públicas:A Experiência da Reunião Especializada sobre Agricultura Familiar do Mercosul. Dados, Rio de Janeiro, 62(2), e20160099. <http://www.scielo.br/scielo.php?script=sci_arttext\&pid=S001152582019000200200\&lng=en\&nrm=iso>. http://dx.doi.org/10.1590/001152582019175. 
Kageyana. A. A. (2008). Desenvolvimento rural: conceitos e aplicação ao caso brasileiro. Porto Alegre. Editora da UFRGS: Programa de Pós-Graduação em Desenvolvimento Rural.

Koutou, M., et al. (2016). Fontes de renda e necessidades de apoio das fazendas familiares na zona oeste do algodão de Burkina Faso. Biotecnologia, Agronomia, Sociedade e Meio Ambiente, 20 (1): pp. 42-56. https://doi.org/10.25518/1780-4507.12648.

Lima, A, M. (2017). Colaboração Interorganizacional e o desenvolvimento socieconômico regional. Holos, v.2, p.239-259. ISSN 1807-1600. <http://www2.ifrn.edu.br/ojs/index.php/HOLOS/article/view/4562>. https://doi.org/10.15628/holos.2017.4562.

Lima, R. de S., \& Fontana, A. P. C. (2019). As feiras da agricultura familiar como território de práticas alimentares e sociabilidades. Redes, Santa Cruz do Sul, 24(3), 75-100. ISSN 1982-6745. <https://online.unisc.br/seer/index.php/redes/article/view/14119>. https://doi.org/10.17058/redes.v24i3.14119.

Nascimento, F. S., \& Beskow, P. R. (2015). Comercialização e Organização dos Produtores Agroecologicos no Rio Grande do Sul - O Estudo Das Experiências da Associação Agricultores Ecologistas de Ipe e Antonio Prado - Aecia e Centro de Apoio ao Pequeno Agricultor. REDES (SANTA CRUZ DO SUL. IMPRESSO), v. 20, p. 261-282

Pereira, C, T., \& GONZALEZ, L. (2017). Atingindo as Exigências dos Agricultores Familiares de Microcrédito através de uniões de crédito: Um Quadro para Discussão. RAM. Revista de Administração Mackenzie 18, no. 5 (2017): 116-143. Redalyc, https://www.redalyc.org/articulo.oa?id=195453538006.

Pena-Rueda., \& Yuri, F. (2019). Caracterização da pecuária por pequenos agricultores no sudoeste de Holguín. Pastagens e Forragens , Matanzas, 42(4), 300-308. <http://scielo.sld.cu/scielo.php?script=sci_arttext\&pid=S0864-03942019000400300\&lng=es\&nrm=iso>

Pierri. M. C. Q. M., \& Valente, A. L. (2011). A feira livre como canal de comercialização de produtos da agricultura familiar. In. Congresso da Sober 48. Campo Grande: NEAD, p.8-20.

Poulain, R. F., \& Souza. D. N. (2018). Economia solidária: outro caminha possível?Colóquio- Revista do Desenvolvimento Regional - Faccat- TaquaralRS, $15(1)$.

Santos, J, G., \& Candido, G, A. (2016). Sustentabilidade e participação social cooperativa de agricultores familiares no agreste da Paraíba / Sustainabilityand social participationcooperativefamilyfarmers in thearid zone of Paraíba. Revista Metropolitana de Sustentabilidade (ISSN 2318-3233), [S.1.], 4(2), 47-63. ISSN 2318-3233. <http://www.revistaseletronicas.fmu.br/index.php/rins/article/view/278>

Santos, M., \& Pontes, A. (2016). Produção e comercialização em assentamentos rurais: estudo do caso do assentamento São Domingos dos Olhos d'àgua (Morrinhos, Goiás - Brasil). Mundo Agrário, 16 (33). http://www.mundoagrario.unlp.edu.ar/article/view/MAv16n33a06.

Shultz, G., de Souza, M., \& Jandrey, W, F. (2017). Motivações e acesso aos canais de comercialização pelos agricultores familiares que atuam com produção orgânica na Região da Serra Gaúcha. Redes (Santa Cruz do Sul. Online), Santa Cruz do Sul, 22(3), 273-291. ISSN 1982-6745. <https://online.unisc.br/seer/index.php/redes/article/view/7627>. https://doi.org/10.17058/redes.v22ie.1627.

Silva, J. M., \& Hespanhol, R. A. de M. (2016). As Estratégias de Reprodução Social dos Agricultores Familiares Das Comunidades Rurais do Município de Catalogo (GO). Geo UERJ, [S.1.], n. 29, p. 402-430. ISSN 1981-9021. <https://www.e-publicacoes.uerj.br/index.php/geouerj/article/view/20304>. https://doi.org/10.12957/geouerj.2016.20304.

Soares, P. (2015). Potencialidades e dificuldades para o abastecimento da alimentação escolar mediante a aquisição de alimentos da agricultura familiar em um município brasileiro. Ciência e saúde coletiva, Rio de Janeiro, 20, n. 6, p. 1891-1900. <http://www.scielo.br/scielo.php?script=sci_arttext\&pid=S141381232015000601891\&lng=en\&nrm=iso>. Doi: http://dx.doi.org/10.1590/1413-81232015206.16972014.

Sposito, E. C., \& de Abreu, L. S. (2017). Diversidade da produção familiar e da comercialização de produtos orgânicos de Vitória (ES). Redes (Santa Cruz do Sul. Online), Santa Cruz do Sul, 22(3), 292-315. ISSN 1982-6745. <https://online.unisc.br/seer/index.php/redes/article/view/6487>. https://doi.org/10.17058/redes.v22i3.6487.

Tesche, R. W., \& Machado, J. A. D. (2013). A Importância da Reciprocidade no Desempenho Socioeconômico da Agricultura Familiar. Estudos do CEPE, Santa Cruz do Sul, p. 7-37. ISSN 1982-6729. <https://online.unisc.br/seer/index.php/cepe/article/view/1563>. https://doi.org/10.17058/cepe.v0i0.1563.

Ploeg. J. D. van der, (2000). Rural development: from practices and policies towards theory. Sociologia Ruralis, 40(14). Http://onlinelibrary.wiley.com.doi\10.1111\1467-952300156lepah

Viegas, I. F. P. (2010). Comércio justo e segurança alimentar. Segurança Alimentar e Nutricional 17(1), 133-143

Vinuto, J. (2014). A amostragem em bola de neve na pesquisa qualitativa: um debate em aberto. Temáticas, 22(44). https://doi.org/10.20396/temáticas.v22i44.10977.

Yin, R. K. (2010). Estudo de caso: planejamento e métodos. Trad. de Daniel Grassi: Bookman, 2010. 